CLINICAL STUDY

\title{
Administration route-dependent effects of estrogens on IGF-I levels during fixed GH replacement in women with hypopituitarism
}

Agatha A van der Klaauw, Nienke R Biermasz, Pierre M J Zelissen ${ }^{1}$, Alberto M Pereira, Eef G W M Lentjes ${ }^{2}$, Johannes W A Smit, Sjoerd W van Thiel, Johannes A Romijn and Ferdinand Roelfsema

Department of Endocrinology and Metabolic Diseases C4-R, Leiden University Medical Centre, PO Box 9600,2300 RC Leiden, The Netherlands,

${ }^{1}$ Department of Endocrinology and ${ }^{2}$ Laboratory of Endocrinology, University Medical Centre Utrecht, Utrecht, The Netherlands

(Correspondence should be addressed to A A van der Klaauw; Email: a.a.van_der_klaauw@lumc.nl)

\begin{abstract}
Objective: GH-deficient women using oral estradiol treatment require higher doses of recombinant human GH (rhGH) to achieve similar IGF-I levels when compared with men and women on transdermal estradiol replacement. The aim of this study was to evaluate the effects of oral versus transdermal estrogen administration at similar plasma estradiol levels on IGF-I, IGF-binding protein-3, and sex hormone-binding globulin (SHBG) concentrations.

Design: Parallel crossover study in which two groups of hypogonadal and GH-deficient women with fixed and stable rhGH replacement passed through four different estradiol treatment schemes ( 2 and $4 \mathrm{mg}$ oral, and 50 and $100 \mu \mathrm{g}$ transdermal estradiol) with a duration of four cycles each to ensure a new steady state. Group I (18 patients using oral estradiol prior to the study) was treated with oral followed by transdermal estradiol and group II (five patients with transdermal estradiol prior to inclusion) with transdermal followed by oral estradiol.

Results: Estradiol concentrations were lowest during $50 \mu \mathrm{g}$ transdermal and highest during $4 \mathrm{mg}$ oral estradiol treatment. Estradiol concentrations did not differ during $100 \mu \mathrm{g}$ transdermal and $2 \mathrm{mg}$ oral treatment. Nevertheless, IGF-I levels were significantly higher during $100 \mu \mathrm{g}$ transdermal when compared with $2 \mathrm{mg}$ oral treatment $(P=0.005$ in group I and 0.02 in group II), while SHBG levels were significantly lower $(P=0.002$ in group I and $P=0.004$ in group II). SHBG and IGF-I concentrations were negatively correlated $(R=-0.41, P=0.0001)$.

Conclusion: During fixed GH replacement, the route of estrogen administration is a determinant of IGF-I levels in hypogonadal GH-deficient women.
\end{abstract}

European Journal of Endocrinology 157 709-716

\section{Introduction}

Clinical studies have demonstrated clear effects of estrogens on growth hormone $(\mathrm{GH})$ production and insulin-like growth factor (IGF)-I levels. Estrogens amplify GH-releasing hormone (GHRH) and insulinstimulated GH release and spontaneous $24 \mathrm{~h} \mathrm{GH}$ production is threefold higher in healthy premenopausal women than in healthy matched men $(1,2)$. Women on estrogen replacement require higher doses of recombinant human $\mathrm{GH}$ (rhGH) replacement than eugonadal women and men to achieve similar IGF-I concentrations (3-5).

Conversely, discontinuation of oral estrogen substitution increases IGF-I levels during continued substitution with rhGH in female patients with hypopituitarism (6). The route of estrogen administration also affects IGF-I levels. A switch from oral to transdermal estrogen therapy increases IGF-I levels and amplifies the IGF-I response during incremental doses of rhGH $(7,8)$. In adult women with GH deficiency (GHD) on a stable rhGH replacement dose, IGF-I levels increased during a switch from oral to transdermal $17 \beta$-estradiol therapy, however, together with a decrease in serum levels of estradiol (7).

Although it has been suggested that these differential effects of transdermal and oral estradiol on the GH/IGF-I axis are due to a first-pass effect of oral estradiol, prior studies in GH-deficient women on stable rhGH replacement were never aimed at identical serum estradiol concentrations. In order to differentiate between the effects of serum estradiol concentrations per se and the route of estrogen administration on IGF-I levels in hypogonadal GH-deficient women, we designed a study to investigate the effects of different doses of oral estradiol ( 2 and $4 \mathrm{mg} /$ day) and different doses of transdermal estradiol (50 and $100 \mu \mathrm{g} /$ day) aimed at identical serum estradiol concentrations on serum concentrations of IGF-I, IGF binding protein-3, and 
sex hormone-binding globulin (SHBG) during rhGH replacement with a fixed dose.

\section{Patients and methods}

\section{Patients}

Twenty-three women with GHD and gonadotropin deficiency were included. Patients were recruited at the Outpatient Clinic of the Leiden University Medical Center and the University Medical Center in Utrecht, the Netherlands.

Inclusion criteria were:

1) GHD defined by a peak GH concentration $<3 \mu \mathrm{g} / \mathrm{l}$ during the insulin tolerance test (nadir blood glucose $<2.2 \mathrm{mmol} / \mathrm{l}$ ),

2) stable rhGH replacement during at least 3 months,

3) oral or transdermal estradiol treatment because of gonadotropin deficiency, and

4) written informed consent.

Patients were enrolled in the two study groups based on their pretreatment (oral and transdermal estradiol), with an individualized dose of GH replacement aimed at achieving a normal IGF-I for age. Eighteen patients started with oral estradiol (of whom 15 completed the study) and five patients with transdermal estradiol. Clinical details are shown in Table 1 . The mean dose of
rhGH replacement during the study was $0.75 \pm$ $0.28 \mathrm{mg} /$ day (range 0.3-1.3 mg/day). Mean duration of rhGH replacement prior to the start of the study was 6 years (range 1-13 years). Conventional substitution therapy was monitored and held stable during the study. The study protocol was approved by the local Ethics Committees.

\section{Study design}

The study was designed as a parallel crossover study. Patients were divided into two groups based on the route of administration of estrogens prior to beginning the study (Fig. 1). The dose of rhGH that had been individually titrated aimed at achieving a normal serum IGF-I for age at the estrogen treatment used prior to inclusion, and during the study this rhGH replacement dose was kept stable.

To avoid carryover effects and to ensure a new steady state, the duration of each estradiol treatment was four cycles of 28 days. In group I, the baseline oral estradiol treatment of $2 \mathrm{mg}$ was first increased to $4 \mathrm{mg}$, and thereafter patients passed through the following treatments: $2 \mathrm{mg}$ oral, and $100 \mu \mathrm{g}$ and $50 \mu \mathrm{g}$ transdermal estradiol. In group II, the baseline treatment of $50 \mu \mathrm{g}$ transdermal estradiol was sequentially increased to $100 \mu \mathrm{g}$ transdermal, and 2 and $4 \mathrm{mg}$ oral estradiol. Because of the necessity to achieve a new steady state at the highest oral estradiol dose, the protocol was four cycles longer in group I. Study parameters during the

Table 1 Characteristics of patients with growth hormone $(\mathrm{GH})$ and gonadotropin deficiency included in the study.

\begin{tabular}{|c|c|c|c|c|c|c|c|}
\hline & Group & Age & Etiology & Treatment & $\begin{array}{l}\text { Pituitary deficiencies } \\
\text { besides GH and } \\
\text { gonadotropin } \\
\text { deficiency }\end{array}$ & $\begin{array}{l}\text { rhGH replacement } \\
\text { dose (mg/day) }\end{array}$ & $\begin{array}{l}\text { Completed } \\
\text { study }\end{array}$ \\
\hline 1 & OR & 21 & Craniopharyngeoma & TSS & ACTH, TSH, ADH & 1.30 & Yes \\
\hline 2 & OR & 45 & M Sheehan & & ACTH, TSH & 1.00 & No \\
\hline 3 & OR & 33 & M Cushing & TSS & ACTH, TSH, ADH & 1.00 & Yes \\
\hline 4 & OR & 36 & Craniopharyngeoma & TCS & $\mathrm{ACTH}, \mathrm{TSH}, \mathrm{ADH}$ & 0.53 & Yes \\
\hline 5 & OR & 46 & Prolactinoma & TSS & TSH & 1.00 & Yes \\
\hline 6 & OR & 64 & $\begin{array}{l}\text { Arachnoidal cyst of } \\
\text { pituitary stalk }\end{array}$ & & ACTH, TSH & 0.80 & No \\
\hline 7 & OR & 51 & M Cushing & TSS & $\mathrm{ACTH}, \mathrm{TSH}, \mathrm{ADH}$ & 1.07 & Yes \\
\hline 8 & OR & 38 & Prolactinoma & TSS \& RT & ACTH, TSH & 0.50 & Yes \\
\hline 9 & OR & 50 & Non-functioning adenoma & TSS & ACTH & 0.30 & Yes \\
\hline 10 & OR & 48 & Non-functioning adenoma & TSS \& RT & ACTH, TSH, ADH & 1.00 & No \\
\hline 11 & OR & 37 & Prolactinoma & TSS \& RT & ACTH, TSH, ADH & 0.80 & Yes \\
\hline 12 & OR & 50 & M Sheehan & & ACTH, TSH & 0.60 & Yes \\
\hline 13 & OR & 32 & M Cushing & TSS \& RT & ACTH, TSH, ADH & 0.80 & Yes \\
\hline 14 & OR & 52 & Non-functioning adenoma & TSS & $\mathrm{ACTH}, \mathrm{TSH}$ & 0.40 & Yes \\
\hline 15 & OR & 40 & Prolactinoma & RT & ACTH, TSH & 0.67 & Yes \\
\hline 16 & OR & 27 & Prolactinoma & TSS \& RT & ACTH, TSH, ADH & 0.50 & Yes \\
\hline 17 & OR & 49 & M Sheehan & & ACTH, TSH & 1.20 & Yes \\
\hline 18 & OR & 50 & M Cushing & TSS & ACTH, TSH & 0.53 & Yes \\
\hline 19 & TD & 45 & Non-functioning adenoma & TSS \& RT & ACTH, TSH & 0.80 & Yes \\
\hline 20 & TD & 41 & Prolactinoma & TSS \& RT & ACTH, TSH & 0.80 & Yes \\
\hline 21 & TD & 54 & M Cushing & TSS & $\mathrm{ACTH}, \mathrm{TSH}$ & 0.80 & Yes \\
\hline 22 & TD & 49 & Epidermoid cyst & TSS & ACTH, TSH & 0.33 & Yes \\
\hline 23 & TD & 48 & M Sheehan & & $\mathrm{ACTH}$ & 0.50 & Yes \\
\hline
\end{tabular}

OR, patients starting with oral estrogen treatment; TD, patients starting with transdermal estrogen treatment; TSS, transsphenoidal surgery; RT, radiotherapy; TCS, transcranial surgery. 


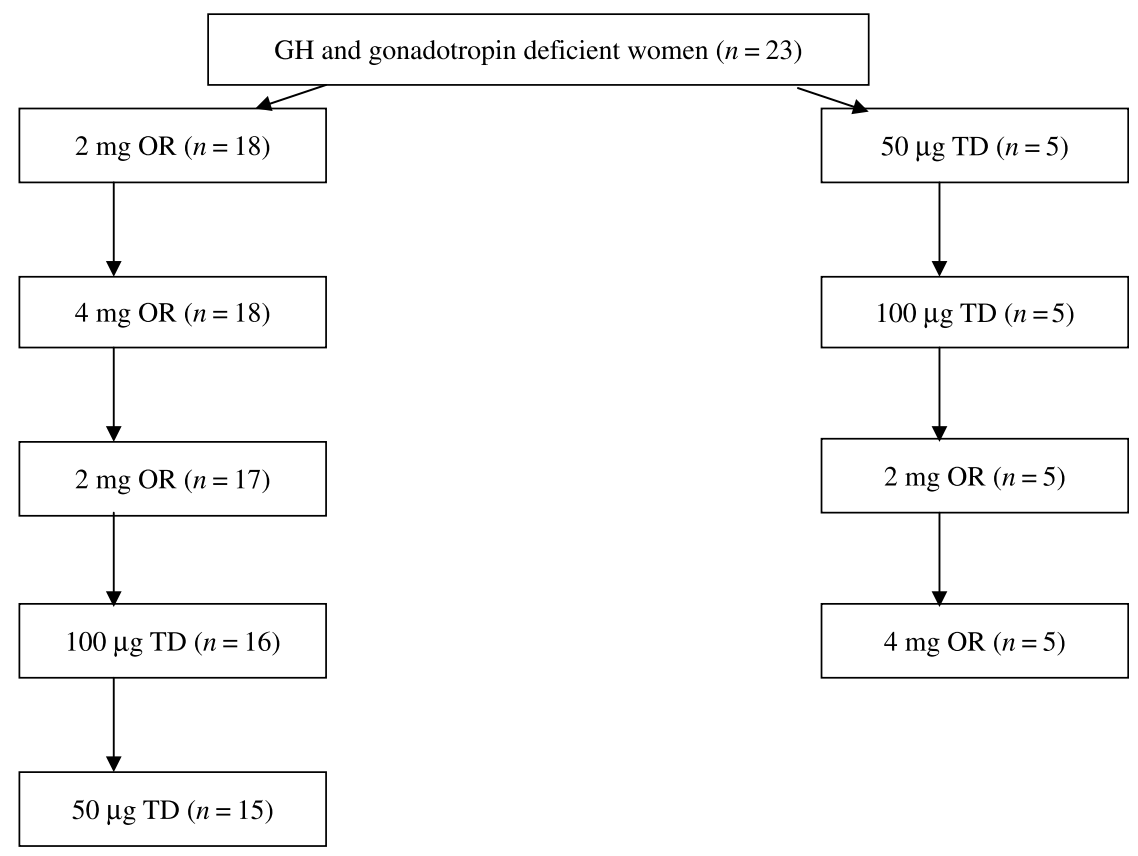

Figure 1 Study design of dose and route of estrogen administration in patients with $\mathrm{GH}$ and gonadotropin deficiency on stable dose rhGH replacement. two periods of estradiol administration (cycles 1 and 9) did not differ, excluding a carryover effect.

Study parameters were measured on day 12 of cycle 1 , before dydrogesteron was added, and during each fourth cycle of 28 days of stable estrogen therapy during the subsequent cycles 5, 9, and 13 in group I and II and cycle 17 in group I only.

\section{Study medication}

Estradiol (2 and 4 mg Estrofem; Novo Nordisk Farma BV, Alphen aan den Rijn, The Netherlands and 50 and $100 \mu$ g Dermestril; Sigma Tau Ethifarma BV) was given with additional dydrogesteron (10 mg Duphaston, Solvay Pharmaceuticals, Weesp, The Netherlands) from days 15 to 28 . Transdermal estrogen patches were used every Monday and Thursday at fixed time points. Tablets were taken every day at fixed time points $(0800$ and $0600 \mathrm{~h})$. The fasting serum estradiol concentrations were assumed to reflect the $24 \mathrm{~h}$ concentrations, because the patients received the Estrofem tablets twice daily, and because of the long apparent half-life of the drug (about $16 \mathrm{~h}$ ) due to the extended resorption phase (9).

\section{Study parameters and assays}

Study parameters were serum levels of IGF-I, IGF-BP3, estradiol, and SHBG. All serum samples were obtained in the fasting state. The serum samples were immediately centrifuged and stored at $-20{ }^{\circ} \mathrm{C}$ until analysis. All samples of all subjects were analyzed simultaneously at the end of the study.
Serum IGF-I was measured using an immunometric technique on an Advantage Chemiluminescence System (Nichols Institute Diagnostics, San Juan Capistrano, CA, USA). The lower limit of detection was $6.0 \mathrm{ng} / \mathrm{ml}$ and the intra-assay variation $(n=250)$ was 8.0 and $6.0 \%$ at mean plasma levels of 30 and $450 \mathrm{ng} / \mathrm{ml}$ respectively. The inter-assay variation was $8.7,5.8$, and $6.5 \%$ at mean IGF-I plasma levels of 33, 174, and $445 \mathrm{ng} / \mathrm{l}$ respectively $(n=115)$. The conversion factor $(\mathrm{ng} / \mathrm{ml}-$ $\mathrm{mmol} / \mathrm{l}$ ) was 7.65 . Serum IGFBP-3 was measured with an in-house RIA, as previously described (10). The lower limit of detection was $0.002 \mathrm{mg} / \mathrm{l}$ (absolute concentration) and the inter-assay variation was $7.5,5.7$, and $7.4 \%$ at mean plasma IGFBP-3 levels of $0.97,2.0$, and $3.0 \mathrm{mg} / \mathrm{l}$ respectively $(n=44)$. Estradiol was measured after diethyl ether extraction and Sephadex chromatography using an in-house competitive RIA. The lower limit of detection for estradiol was $20 \mathrm{pmol} / \mathrm{l}$ ( $2 \mathrm{ml}$ sample). The inter-assay variation was 12 and $3 \%$ at 80 and $660 \mathrm{pmol} / \mathrm{l}$ respectively $(n=45$, resp. 25$)$. We measured SHBG with an immunometric technique on an Immulite analyzer (Diagnostic Products Corporation, Los Angeles, CA, USA). The lower limit of detection was $5 \mathrm{nmol} / \mathrm{l}$ and inter-assay variation was $5.5,4.1$, and $5.3 \%$ at 14,34 , and $91 \mathrm{nmol} / \mathrm{l}$ respectively $(n=23)$.

\section{Statistical analysis}

Statistical analysis was performed using Systat, version 11 (Systat Software, Richmond, CA, USA). Results are shown as the mean \pm S.E.M., unless specified otherwise. A $P$ value $<0.05$ was assumed to represent a significant difference. 
Patients were divided into two groups based on prior oral or transdermal estrogen treatment (see study design) and groups were analyzed separately. Raw data were logarithmic-transformed and equality of the variances at each time period was verified with the Bartlett and the Levene tests. The serial data of both groups were analyzed by ANOVA with repeated measures with a general linear model. The statistical significance between the contrasts was corrected with the Bonferroni procedure for multiple comparisons in the post hoc tests in group $\mathrm{I}$.

\section{Results}

\section{Patients}

Of the 23 patients included, 20 completed the four different treatments (Fig. 1). Mean age was 44.2 \pm 9.6 years and mean body mass index (BMI) was 28.5 \pm $6.7 \mathrm{~kg} / \mathrm{m}^{2}$. Reasons for withdrawal were aggravated menstrual blood loss $(n=1)$ and fluid retention $(n=1)$, both during $2 \mathrm{mg}$ oral (OR), and personal reasons $(n=1)$ during $100 \mu \mathrm{g}$ transdermal (TD) estradiol.

\section{High- versus low-dose estrogen administration}

The individual hormone concentrations in the two groups are plotted in Fig. 2 and the relevant statistical details are listed in Table 2. The lowest estradiol concentrations were measured during $50 \mu \mathrm{g}$ TD estradiol administration and the highest during $4 \mathrm{mg}$ OR. Estradiol concentrations were approximately twofold higher during the higher OR and TD doses when compared with lower OR and TD doses. The mean serum estradiol concentrations were not statistically different between the $2 \mathrm{mg}$ OR and the $100 \mu \mathrm{g}$ TD treatment period $(P=1.0)$.

During the high oral estrogen dose $(4 \mathrm{mg})$ when compared with the low (2 mg), serum IGF-I was significantly lower $(97 \pm 8.4$ vs $140 \pm 13.8 \mu \mathrm{g} / \mathrm{l}$, $P=0.003$ in group I and $P=0.04$ in group II), while SHBG concentration was higher $(P<0.002)$ and serum IGFBP-3 was not significantly different.

Although during the transdermal dose of $50 \mu \mathrm{g}$ estradiol the lowest mean estradiol and SHBG concentrations and higher mean IGF-I and IGF-BP3 concentrations were measured when compared with those obtained during the $100 \mu \mathrm{g}$ TD dose, the differences were not statistically significant (please refer to Table 2).

\section{Oral (2 mg) versus transdermal (100 $\mu \mathrm{g})$ estrogen administration}

Estradiol concentrations measured during $2 \mathrm{mg}$ OR and $100 \mu \mathrm{g}$ TD estradiol were not statistically different. Despite comparable estradiol concentration, serum IGFI was significantly lower in the $2 \mathrm{mg}$ OR when compared with the $100 \mu \mathrm{g}$ TD period $(P=0.005$ in group I and $P=0.02$ in group II), while SHBG concentrations were significantly higher $(P=0.002$ in group I and $P=0.004$ in group II). Serum SHBG and IGF-I concentrations were
Group I
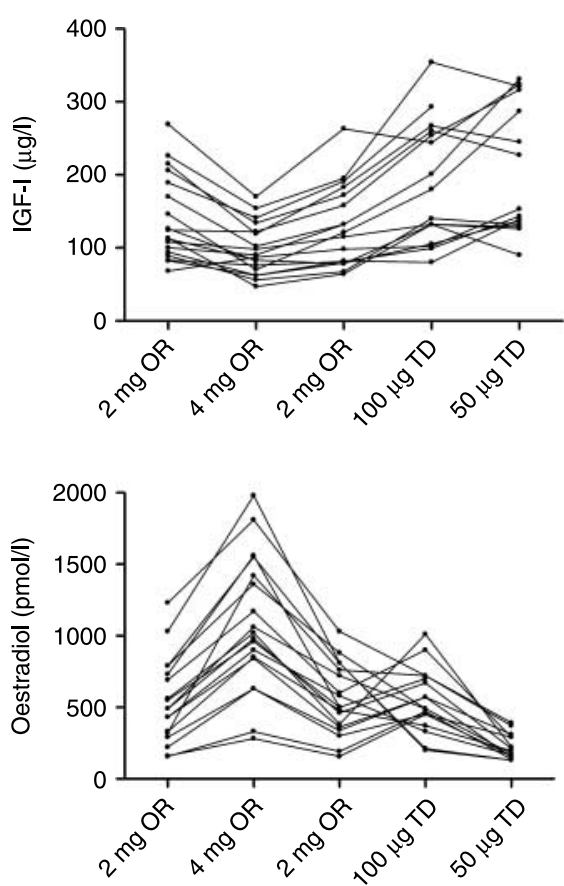

Group II
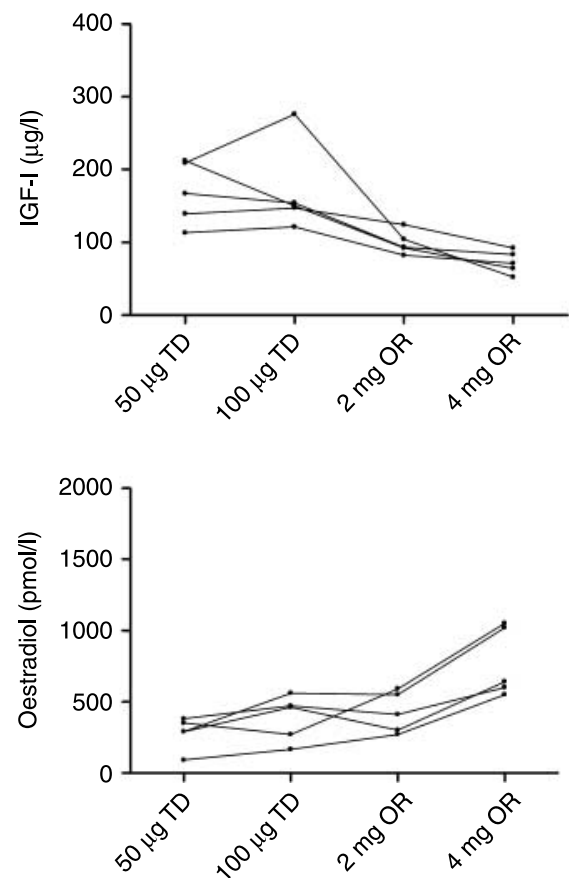

Figure 2 Individual plots of IGF-I (upper panels) and estradiol (lower panels) in hypogonadal GH-deficient females during a fixed dose of $\mathrm{GH}$ replacement and different doses of oral and transdermal estradiol replacement. Statistical details are listed in Table 2. 
Table 2 Serum hormone concentrations in female growth hormone (GH)-deficient patients during GH and estrogen replacement.

\begin{tabular}{|c|c|c|c|c|}
\hline & $2 \mathrm{mg}$ OR & $4 \mathrm{mg}$ OR & $50 \mu \mathrm{g}$ TD & $100 \mu \mathrm{g}$ TD \\
\hline \multicolumn{5}{|l|}{ OR to TD group I } \\
\hline IGF-I $(\mu \mathrm{g} / \mathrm{l})$ & $140 \pm 13.8^{*}$, & $97 \pm 8.4^{\dagger}$ & $206 \pm 23$ & $186 \pm 21$ \\
\hline Estradiol (pmol/l) & $540 \pm 70^{\S, 9}$ & $1070 \pm 111$ & $221 \pm 23$ & $552 \pm 57^{\prime \prime}$ \\
\hline IGFBP-3 (mg/l) & $2.1 \pm 0.1$ & $1.9 \pm 0.1$ & $2.4 \pm 0.2^{\mathrm{a}}$ & $2.3 \pm 0.2$ \\
\hline SHBG $(\mathrm{nmol} / \mathrm{l})$ & $135 \pm 13^{\mathrm{b}, \mathrm{c}}$ & $174 \pm 14^{\mathrm{C}}$ & $65 \pm 6$ & $95 \pm 12$ \\
\hline \multicolumn{5}{|l|}{ TD to OR group II } \\
\hline IGF-I $(\mu \mathrm{g} / \mathrm{l})$ & $99 \pm 7.1^{\mathrm{d}, \mathrm{e}}$ & $72 \pm 7$ & $168 \pm 19$ & $170 \pm 27$ \\
\hline Estradiol (pmol/l) & $424 \pm 64^{\mathrm{f}, g}$ & $772 \pm 108$ & $280 \pm 51$ & $385 \pm 72$ \\
\hline IGFBP-3 (mg/l) & $1.8 \pm 0.1$ & $1.6 \pm 0.1$ & $2.0 \pm 0.1$ & $2.1 \pm 0.1$ \\
\hline SHBG $(\mathrm{nmol} / \mathrm{l})$ & $120 \pm 26^{\mathrm{h}, \mathrm{i}}$ & $153 \pm 28$ & $70 \pm 13$ & $88 \pm 21$ \\
\hline
\end{tabular}

Data are shown as mean + S.E.M. Data were analyzed by ANOVA for repeated measures. Significance was tested with the Bonferroni correction for multiple comparisons. ${ }^{\star} P=0.005$ vs $100 \mu \mathrm{g} \mathrm{TD} ;{ }^{\dagger} P<0.0001$ vs $50 \mu \mathrm{g}$ and $100 \mu \mathrm{g} \mathrm{TD} ;{ }^{\ddagger} P=0.003 \mathrm{vs} 4 \mathrm{mg} \mathrm{OR} ;{ }^{\S} P<0.0001$ vs $4 \mathrm{mg}$ OR; ${ }^{\|} P<0.0001 \mathrm{vs} 50 \mu \mathrm{g}$ TD; ${ }^{\pi} P=0.01$ vs $50 \mu \mathrm{g}$ TD; ${ }^{\mathrm{a}} P<0.001 \mathrm{vs} 4 \mathrm{mg}$ OR; ${ }^{\mathrm{b}} P<0.002 \mathrm{vs} 4 \mathrm{mg}$ OR; ${ }^{\mathrm{c}} P=0.002$ vs 50 and $100 \mu \mathrm{g}$ TD; ${ }^{\mathrm{d}} P=0.04$ vs $4 \mathrm{mg}$ OR; ${ }^{\mathrm{e}} P=0.02 \mathrm{vs} 100 \mu \mathrm{g}$ TD; ${ }^{\mathrm{f}} P=0.007$ vs $4 \mathrm{mg}$ OR; ${ }^{9} P=0.07$ vs $50 \mu \mathrm{g} \mathrm{TD} ;{ }^{\mathrm{h}} P=0.004$ vs $100 \mu \mathrm{g}$ TD; ${ }^{i} P=0.02$ vs $4 \mathrm{mg}$ OR.

negatively correlated in a linear model $(R=-0.41$, $P=0.0001)$.

\section{Side effects}

Patients of group I especially had physical complaints during the use of the $50 \mu \mathrm{g}$ estradiol dermal patch. Eight patients experienced muscle pains, two had arthralgias, and four carpal tunnel syndrome. The complaints quickly disappeared when the patients were switched again to oral estradiol after completion of the trial. In group II IGF-I concentrations were above two standard deviation scores during 100 and $50 \mu \mathrm{g}$ TD, indicating clear over-treatment in three of five cases respectively.
In the other group, the most important complaints were increase in weight and emotional lability during the high-dose estradiol period.

\section{Discussion}

This study was designed to differentiate between the effects of serum estradiol concentrations per se and the route of estrogen administration on IGF-I levels in women with GH and gonadotropin deficiency. Each subject was kept on a fixed dose of rhGH during the whole study. Oral administration of estradiol resulted in lower IGF-I levels when compared with transdermal
Group I
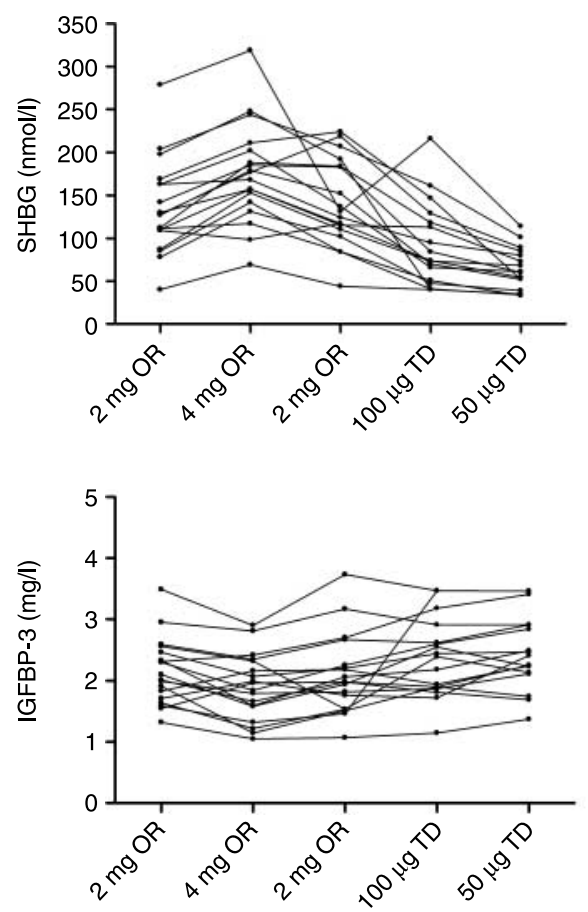

Group II
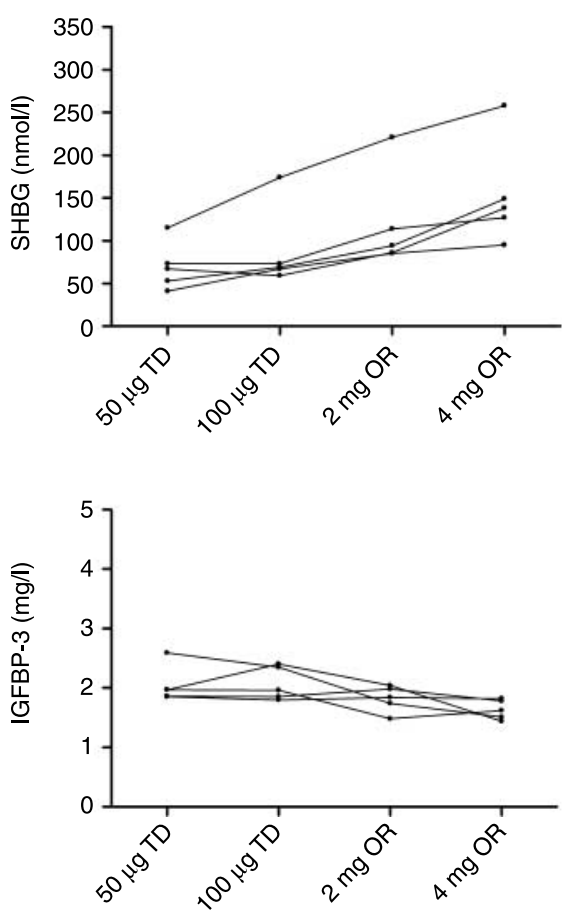

Figure 3 Individual plots of SHBG (upper panels) and IGFBP3 (lower panels) in hypogonadal $\mathrm{GH}$-deficient females during a fixed dose of $\mathrm{GH}$ replacement and different doses of oral and transdermal estradiol replacement. Statistical details are listed in Table 2. 
administration, in accordance with previous studies that were not aimed at achieving comparable estradiol concentrations $(7,8)$. IGF-I levels were higher during transdermal administration of $100 \mu \mathrm{g} 17 \beta$-estradiol when compared with oral administration of $2 \mathrm{mg}$ $17 \beta$-estradiol while circulating estradiol concentrations were similar. Therefore, we conclude that the route of estradiol administration is a determinant of IGF-I levels during fixed rhGH replacement.

Serum IGF-I concentrations decreased when increasing oral dose of estrogen treatment or increased after discontinuation of estrogen replacement as shown by studies in GH-deficient women (Table $3(6,11,12))$. In two other crossover studies aimed at unraveling the effects of different routes of estrogen administration on IGF-I concentrations, patients received both transdermal and oral estrogen replacement (Table $3(7,8)$ ). In the first crossover study, IGF-I levels increased in women on a fixed rhGH replacement dose during the switch from oral to transdermal estrogen therapy, but after the switch serum levels of estradiol decreased, which could have contributed to the IGF-I increase (7). The second crossover study compared the IGF-I concentrations with the baseline values. In that study $\mathrm{GH}$ administration increased IGF-I levels in a stepwise dose-dependent manner during both estrogen administration routes, but IGF-I concentrations were lower during oral estradiol than transdermal administration at all used GH doses (8). Also in healthy postmenopausal women with an intact GH/IGF-I axis, oral estrogen administration reduces IGF-I concentrations, whereas transdermal estrogen administration has a variable effect (13-15).

The hypothalamic-somatotrope-IGF-I axis is primarily driven by GHRH, ghrelin, and somatostatin and restrained by the negative feedback of liver-derived IGF-I, which acts upon the somatotrope and hypothalamic centers in a complex interplay (1). In addition, other hormones and metabolic signals modulate this system. Pathophysiological studies in postmenopausal women have revealed a central $\mathrm{GH}$-stimulating role for estradiol $(16,17)$. Therefore, for precise studies of IGF-I modulation by estrogens it is crucial that GH is fixed, as in the present study.

Estradiol is rapidly absorbed from the gastrointestinal tract, but undergoes extensive first-pass effects resulting in the conversion into various metabolites. In pigs, only $6 \%$ of orally administered estradiol is present as such in the portal vein, whereas the remainder is metabolized into estrone and glucuronide and sulfate conjugates of estradiol and estrone (18). Most of the portal estradiol is rapidly cleared into the systemic circulation (19). Therefore, similar plasma estradiol concentrations can be reached only during oral estradiol treatment when compared with transdermal estradiol treatment at the expense of high estrogen exposure to the liver. In accordance with this notion, we found that SHBG concentrations, a reflection of estrogen exposure of the liver (20), were the highest during oral estrogen

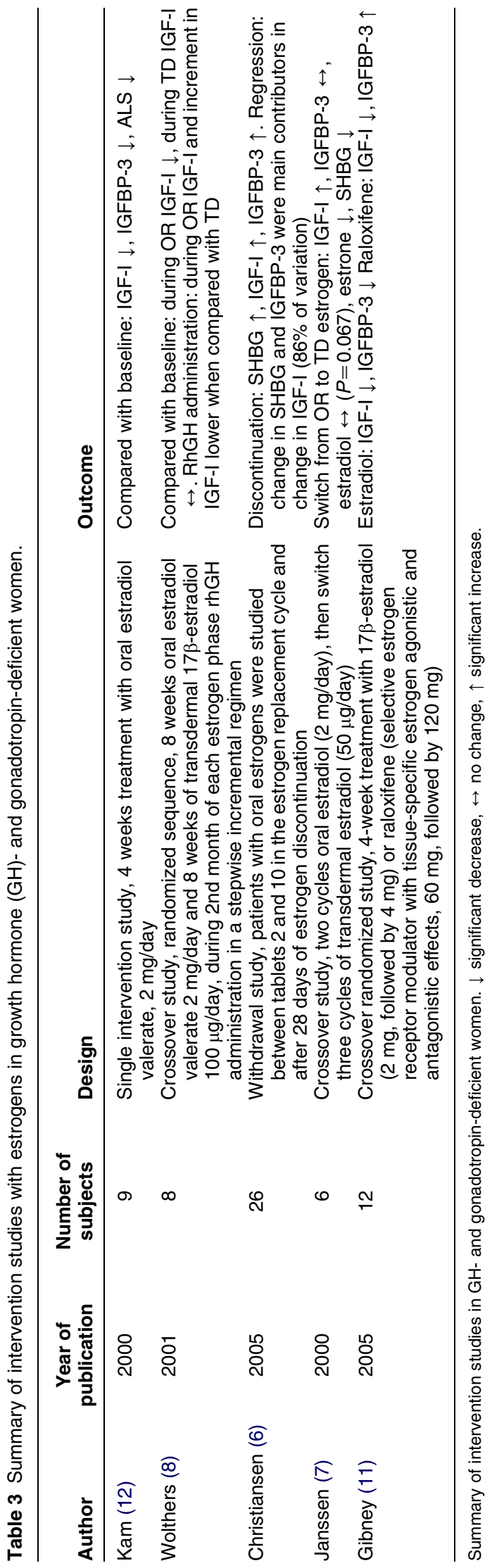


treatment when compared with transdermal treatment. Nevertheless, the inhibitory effect on serum IGF-I concentration can also be accomplished using large (non-physiological) doses of transdermal estradiol, thus underscoring that the hepatic estradiol effects on IGF-I, SHBG, corticosteroid binding globulin (CBG), clotting factors, and CRP are liver specific rather than route specific (21). In the model we used, the differential effects of oral and transdermal estrogen administration on IGF-I levels were explained by different degrees of estrogen exposure of the liver. We found the well-known dosedependent estrogen effects on serum IGF-I, but also a $\sim 25 \%$ mean reduction of IGF-I by the first-pass effect of oral administration.

Several animal studies have shown the relationship between estrogen treatment and hepatic IGF-I RNA expression. In ovariectomized rats, replacement with estradiol dose-dependently suppressed hepatic IGF-I liver mRNA expression and plasma IGF-I concentrations $(22,23)$. Recently, the molecular mechanism underlying the hepatic effect of estrogen on IGF-I synthesis was discovered. GH signaling via the Janus kinase-signal transducer and activation of transcription (JAK-STAT) pathway is inhibited by the suppression of JAK2 phosphorylation through stimulation of the suppressors of cytokine signalling (SOCS-2) pathway (24). These basal mechanisms explain the gender difference that is observed in GH sensitivity, for example, in the treatment of GH-deficient patients (25).

IGFBP-3 concentrations were the lowest during $4 \mathrm{mg}$ oral estrogen therapy, but the changes in this study were limited and also other studies report conflicting data on the estrogen effect on IGFBP-3. Either no effect (in normal pre- and postmenopausal women) $(13,15)$ or a decrease was observed (in postmenopausal women and hypogonadal GH-deficient patients after oral estrogen administration) $(11,12)$, while no changes were seen after transdermal estrogen administration. Although the limited changes in IGFBP-3 may be caused by the decrease of IGF-I, direct inhibition of IGFBP-3 synthesis and release from Kupfer cells are also possible (24). It is important to note that IGFBP-3 is of limited use in clinical practice to detect changes in disease activity of $\mathrm{GH}$ disorders.

The changes in SHBG levels after estrogen treatment were found to be dose dependent, with the highest SHBG concentrations during oral estrogen treatment. Serum SHBG concentrations correlated negatively with IGF-I concentrations, as reported by others in healthy subjects and in $\operatorname{GHD}(6,26)$. Moreover, SHBG levels were lower during transdermal administration of $100 \mu \mathrm{g}$ estradiol when compared with oral administration of $2 \mathrm{mg}$ estradiol, despite similar circulating estradiol concentrations. Therefore, the route of estrogen administration is also a determinant of SHBG levels.

In this study, we could not include naïve untreated gonadotropin and GH-deficient premenopausal women. Consequently, a randomization procedure was not possible and the preference of patients and physicians for oral estradiol substitution is reflected in the unbalanced number of patients between the two groups. Because of the limited number of patients (in group II) and the four different estrogen treatments that had to be compared, the groups were separately analyzed, although no group effects or carryover effects were present. Although probably due to the lesser number of patients in group II some of the changes did not reach significance, it is interesting to note that the changes in this group were comparable with the changes observed in group I. The additive value of group II is that the results of this study are valid for interventions leading to IGF-I concentrations both in the supraphysiological range (group I) and in the subphysiological range (group II). When the two groups were analyzed together, the conclusions remained unaltered (data not shown), particularly for the comparisons of IGF-I, IGFBP-3, and SHBG during $2 \mathrm{mg}$ oral estrogen treatment and $100 \mu \mathrm{g}$ transdermal estrogen treatment.

From a cost-effective point of view of GH substitution, transdermal estrogen replacement is preferred. Patients who are switched from oral to transdermal estrogen replacement require $\sim 0.3 \mathrm{mg} \mathrm{GH}$ less per day which on a nationwide scale is a considerable cost reduction (27). Leung et al. have calculated a cost reduction for the USA population of $\$ 110$ billion or approximately $\$ 4400$ per patient (27).

In summary, the route of estrogen administration is a determinant of serum IGF-I concentrations in adult women with $\mathrm{GH}$ and gonadotropin deficiency during fixed rhGH replacement.

\section{Acknowledgements}

The authors would like to acknowledge Prof. Dr F M Helmerhorst from the Department of Gynecology, Leiden University Medical Center, and Mrs I Maitimu from the Laboratory of Endocrinology, University Medical Center Utrecht.

\section{References}

1 Giustina A \& Veldhuis JD. Pathophysiology of the neuroregulation of growth hormone secretion in experimental animals and the human. Endocrine Reviews 199819 717-797.

2 van den BG, Veldhuis JD, Frolich M \& Roelfsema F. An amplitudespecific divergence in the pulsatile mode of growth hormone $(\mathrm{GH})$ secretion underlies the gender difference in mean GH concentrations in men and premenopausal women. Journal of Clinical Endocrinology and Metabolism 199681 2460-2467.

3 Cook DM, Ludlam WH \& Cook MB. Route of estrogen administration helps to determine growth hormone $(\mathrm{GH})$ replacement dose in GH-deficient adults. Journal of Clinical Endocrinology and Metabolism 199984 3956-3960.

4 Johansson AG, Engstrom BE, Ljunghall S, Karlsson FA \& Burman P. Gender differences in the effects of long term growth hormone $(\mathrm{GH})$ treatment on bone in adults with GH deficiency. Journal of Clinical Endocrinology and Metabolism 199984 2002-2007. 
5 Span JP, Pieters GF, Sweep CG, Hermus AR \& Smals AG. Gender difference in insulin-like growth factor I response to growth hormone (GH) treatment in GH-deficient adults: role of sex hormone replacement. Journal of Clinical Endocrinology and Metabolism 2000 85 1121-1125.

6 Christiansen JJ, Fisker S, Gravholt CH, Bennett P, Svenstrup B, Andersen M, Feldt-Rasmussen U, Christiansen JS \& Jorgensen JO. Discontinuation of estrogen replacement therapy in GH-treated hypopituitary women alters androgen status and IGF-I. European Journal of Endocrinology 2005152 719-726.

7 Janssen YJ, Helmerhorst F, Frolich M \& Roelfsema F. A switch from oral ( $2 \mathrm{mg} /$ day) to transdermal ( $50 \mu \mathrm{g} /$ day) 17 beta-estradiol therapy increases serum insulin-like growth factor-I levels in recombinant human growth hormone (GH)-substituted women with GH deficiency. Journal of Clinical Endocrinology and Metabolism 200085 464-467.

8 Wolthers T, Hoffman DM, Nugent AG, Duncan MW, Umpleby M \& Ho KK. Oral estrogen antagonizes the metabolic actions of growth hormone in growth hormone-deficient women. American Journal of Physiology. Endocrinology and Metabolism 2001281 E1191-E1196.

9 Fink BJ \& Christensen MS. Bioavailability of oestradiol and oestriol administered orally to oophorectomized women. Maturitas 19813 289-294.

10 de Vries BB, Robinson H, Stolte-Dijkstra I, Tjon Pian Gi CV, Dijkstra PF, van Doorn J, Halley DJ, Oostra BA, Turner G \& Niermeijer MF. General overgrowth in the fragile $\mathrm{X}$ syndrome: variability in the phenotypic expression of the FMR1 gene mutation. Journal of Medical Genetics 199532 764-769.

11 Gibney J, Johannsson G, Leung KC \& Ho KK. Comparison of the metabolic effects of raloxifene and oral estrogen in postmenopausal and growth hormone-deficient women. Journal of Clinical Endocrinology and Metabolism 200590 3897-3903.

12 Kam GY, Leung KC, Baxter RC \& Ho KK. Estrogens exert route- and dose-dependent effects on insulin-like growth factor (IGF)-binding protein-3 and the acid-labile subunit of the IGF ternary complex. Journal of Clinical Endocrinology and Metabolism 2000 85 1918-1922.

13 Lissett CA \& Shalet SM. The impact of dose and route of estrogen administration on the somatotropic axis in normal women. Journal of Clinical Endocrinology and Metabolism $2003 \mathbf{8 8}$ 4668-4672.

14 Paassilta M, Karjalainen A, Kervinen K, Savolainen MJ, Heikkinen J, Backstrom AC \& Kesaniemi YA. Insulin-like growth factor binding protein-1 (IGFBP-1) and IGF-I during oral and transdermal estrogen replacement therapy: relation to lipoprotein(a) levels. Atherosclerosis 2000149 157-162.

15 Bellantoni MF, Vittone J, Campfield AT, Bass KM, Harman SM \& Blackman MR. Effects of oral versus transdermal estrogen on the growth hormone/insulin-like growth factor I axis in younger and older postmenopausal women: a clinical research center study. Journal of Clinical Endocrinology and Metabolism $1996 \mathbf{8 1}$ 2848-2853.

16 Veldhuis JD, Evans WS \& Bowers CY. Estradiol supplementation enhances submaximal feed-forward drive of growth hormone $(\mathrm{GH})$ secretion by recombinant human GH-releasing hormone-1,44amide in a putatively somatostatin-withdrawn milieu. Journal of Clinical Endocrinology and Metabolism $2003 \mathbf{8 8} 5484-5489$.

17 Veldhuis JD, Anderson SM, Kok P, Iranmanesh A, Frystyk J, Orskov H \& Keenan DM. Estradiol supplementation modulates growth hormone $(\mathrm{GH})$ secretory-burst waveform and recombinant human insulin-like growth factor-I-enforced suppression of endogenously driven GH release in postmenopausal women. Journal of Clinical Endocrinology and Metabolism 200489 1312-1318.

18 Ruoff WL \& Dziuk PJ. Absorption and metabolism of estrogens from the stomach and duodenum of pigs. Domestic Animal Endocrinology 199411 197-208.

19 Scharl A, Beckmann MW, Artwohl JE, Kullander S \& Holt JA. Rapid liver metabolism, urinary and biliary excretion, and enterohepatic circulation of 16 alpha-radioiodo-17 beta-estradiol. International Journal of Radiation Oncology, Biology, Physics 199121 1235-1240.

20 Stomati M, Hartmann B, Spinetti A, Mailand D, Rubino S, Albrecht A, Huber J, Petraglia F \& Genazzani AR. Effects of hormonal replacement therapy on plasma sex hormone-binding globulin, androgen and insulin-like growth factor-1 levels in postmenopausal women. Journal of Endocrinological Investigation 1996 19 535-541.

21 Friend KE, Hartman ML, Pezzoli SS, Clasey JL \& Thorner MO. Both oral and transdermal estrogen increase growth hormone release in postmenopausal women - a clinical research center study. Journal of Clinical Endocrinology and Metabolism 199681 2250-2256.

22 Borski RJ, Tsai W, DeMott-Friberg R \& Barkan AL. Regulation of somatic growth and the somatotropic axis by gonadal steroids: primary effect on insulin-like growth factor I gene expression and secretion. Endocrinology 1996137 3253-3259.

23 Krattenmacher R, Knauthe R, Parczyk K, Walker A, Hilgenfeldt U \& Fritzemeier KH. Estrogen action on hepatic synthesis of angiotensinogen and IGF-I: direct and indirect estrogen effects. Journal of Steroid Biochemistry and Molecular Biology 199448 207-214.

24 Leung KC, Doyle N, Ballesteros M, Sjogren K, Watts CK, Low TH, Leong GM, Ross RJ \& Ho KK. Estrogen inhibits GH signaling by suppressing GH-induced JAK2 phosphorylation, an effect mediated by SOCS-2. PNAS $2003 \mathbf{1 0 0} 1016-1021$.

25 Janssen YJ, Frolich M \& Roelfsema F. A low starting dose of genotropin in growth hormone-deficient adults. Journal of Clinical Endocrinology and Metabolism 199782 129-135.

26 Pfeilschifter J, Scheidt-Nave C, Leidig-Bruckner G, Woitge HW, Blum WF, Wuster C, Haack D \& Ziegler R. Relationship between circulating insulin-like growth factor components and sex hormones in a population-based sample of 50- to 80-year-old men and women. Journal of Clinical Endocrinology and Metabolism $1996812534-2540$.

27 Leung KC, Johannsson G, Leong GM \& Ho KK. Estrogen regulation of growth hormone action. Endocrine Reviews 200425 693-721.

Received 3 August 2007

Accepted 1 October 2007 